\title{
Caffeoylxanthiazonoside exerts cardioprotective effects during chronic heart failure via inhibition of inflammatory responses in cardiac cells
}

\author{
BIN YANG ${ }^{1}$, FEI WANG ${ }^{1}$, HUILI CAO ${ }^{1}$, GUIFANG LIU $^{1}$, YUEAN ZHANG $^{2}$, PING YAN $^{3}$ and BAO LI ${ }^{4}$ \\ Departments of ${ }^{1}$ Cardiology and ${ }^{2}$ Science and Education, Shanxi Cardiovascular Hospital, Taiyuan, Shanxi 030024; \\ ${ }^{3}$ Department of Biochemistry and Molecular Biology, College of Basic Medicine, Shanxi Medical University; \\ ${ }^{4}$ Department of Cardiology, The Second Hospital of Shanxi Medical University, Taiyuan, Shanxi 030001, P.R. China
}

Received September 30, 2016; Accepted June 5, 2017

DOI: 10.3892/etm.2017.5080

\begin{abstract}
Caffeoylxanthiazonoside (CYT) is an active constituent isolated from the fruit of the Xanthium strumarium $\mathrm{L}$ plant. The aim of the present study was to investigate the cardioprotective effects of oral administration of CYT on chronic heart failure (CHF) and its underlying mechanisms. A rat model of CHF was first established, and cardiac function indices, including the heart/body weight index, left heart/body weight index, fractional shortening (FS), ejection fraction (EF), cardiac output (CO) and heart rate (HR), were subsequently determined by cardiac ultrasound. Serum levels of lactate dehydrogenase ( $\mathrm{LDH})$ and creatine kinase $(\mathrm{CK})$, and the levels of pro-inflammatory cytokines, including tumor necrosis factor (TNF)- $\alpha$, interleukin (IL)- 6 and IL-1 $\beta$ in heart tissues and cardiac microvascular endothelial cells (CMECs) were determined using ELISA. In addition, the protein expression levels of nuclear factor $-\kappa \mathrm{B}(\mathrm{NF}-\kappa \mathrm{B})$ signaling pathway members were determined by western blotting in CMECs. The results demonstrated that oral administration of 10, 20, $40 \mathrm{mg} / \mathrm{kg}$ CYT significantly reduced cardiac hypertrophy and reversed FS, EF, CO and HR when compared with $\mathrm{CHF}$ model rats. In addition, CYT administration significantly decreased the levels of TNF- $\alpha$, IL- 6 and IL-1 $\beta$ in heart tissues, as well as serum LDH and CK levels. Furthermore, exposure of CMECs
\end{abstract}

Correspondence to: Dr Ping Yan, Department of Biochemistry and Molecular Biology, College of Basic Medicine, Shanxi Medical University, 56 South Xinjian Road, Taiyuan, Shanxi 030001, P.R. China

E-mail: meduniyp@163.com

Dr Bao Li, Department of Cardiology, The Second Hospital of Shanxi Medical University, 382 Wuyi Road, Taiyuan, Shanxi 030001, P.R. China

E-mail: sxmeduni@163.com

Key words: Xanthium strumarium L., caffeoylxanthiazonoside, inflammatory cytokines, nuclear factor- $\kappa \mathrm{B}$ pathway, cardioprotective effects to 20,40 and $80 \mu \mathrm{g} / \mathrm{ml} \mathrm{CYT} \mathrm{significantly} \mathrm{decreased} \mathrm{the}$ production of TNF- $\alpha$, IL-1 $\beta$ and IL- 6 . The protein expression levels of cytoplasmic NF- $\kappa$ B p65 and I $\mathrm{B}$ were upregulated, while nuclear $\mathrm{NF}-\kappa \mathrm{B}$ p65 was downregulated following treatment of CMECs with 20, 40 and $80 \mu \mathrm{g} / \mathrm{ml} \mathrm{CYT}$ when compared with untreated CHF model controls. In conclusion, the results of the current study suggest that CYT demonstrates cardioprotective effects in $\mathrm{CHF}$ model rats by suppressing the expression of pro-inflammatory cytokines and the $\mathrm{NF}-\kappa \mathrm{B}$ signaling pathway.

\section{Introduction}

In recent years, heart failure (HF) has become a global health problem and is a serious threat to human health (1). Chronic heart failure (CHF) is a relatively stable state of $\mathrm{HF}$, and is a clinical syndrome with a complex pathophysiology. CHF is used to describe any functional or structural disorder that affects the heart and prevents the ventricles from pumping blood efficiently and/or the heart chambers filling completely $(2,3)$. According to current treatment guidelines, the available treatments for patients with $\mathrm{CHF}$ include angiotensin receptor inhibitors or angiotensin-converting enzyme inhibitors, diuretics, $\beta$-blockers, aldosterone receptor antagonists, vasodilating agents and digitalis (4). However, the use of these drugs is limited by their serious side effects $(5,6)$. In addition, despite significant advances in the diagnosis and treatment of patients with $\mathrm{CHF}$, their prognoses remains poor, with an unacceptably high risk of mortality (7). Therefore, there is an urgent requirement for the identification of novel therapeutic agents that effectively treat patients with $\mathrm{CHF}$ and exhibit fewer side effects.

Xanthium strumarium L. (X. strumarium), from the Asteraceae family, is a medicinal plant distributed widely in North America, Brazil, China, Malaysia, and regions of India with warm climates (8). The $X$. strumarium fruits (also known as 'Cangerzi' in Chinese) are traditionally used to treat rhinitis, rheumatism, tuberculosis, cancer, ulcers and malaria (9). A previous report demonstrated that $X$. strumarium contains a number of chemical constituents, including flavones, saponins, affeyolquinic acids, caffeic acids, 
and sesquiterpene lactones (10). Caffeoylxanthiazonoside (CYT; 7-hydroxymethyl-8,8-dimethyl-4,8-dihydrobenzol), a thiazinedione heterocyclic compound isolated from the fruits of $X$. strumarium, has been reported to possess significant anti-allergy, anti-inflammatory and analgesic properties $(10,11)$. However, to the best of the author's knowledge, no studies published to date have investigated the cardioprotective effects of CYT. Therefore, in the present study, a rat model of $\mathrm{CHF}$ was generated to investigate the cardioprotective effects of CYT isolated from the fruits of X. strumarium. The results suggest that this compound may be beneficial for the clinical treatment of patients with $\mathrm{CHF}$ in the future.

\section{Materials and methods}

Chemicals and reagents. Dulbecco's modified Eagle's medium (DMEM)-F12, fetal bovine serum (FBS) and radioimmunoprecipitation assay (RIPA) lysis buffer were purchased from Invitrogen; Thermo Fisher Scientific, Inc. (Waltham, MA, USA). Creatine kinase (CK) (cat. no. A032) and lactate dehydrogenase (LDH) (cat. no. A020-2) assay kits, and pentobarbital were purchased from Nanjing Jiancheng Bioengineering Institute (Nanjing, China). Tumor necrosis factor (TNF)- $\alpha$ (cat. no. RTA00), interleukin (IL)-6 (cat. no. R6000B) and IL-1 $\beta$ (cat. no. RLB00) ELISA kits were purchased from R\&D Systems China Co., Ltd. (Shanghai, China). The bicinchoninic acid assay (BCA) kit and primary antibodies against nuclear factor $-\kappa \mathrm{B}(\mathrm{NF}-\kappa \mathrm{B}) \mathrm{p} 65$ (cat. no. AN371; dilution, 1:1,000), IкB (cat. no. AI096; dilution, 1:1,000) were obtained from Beyotime Institute of Biotechnology (Haimen, China). The primary antibody against histone H1 (cat. no, ab203337; dilution, 1:1,000) and GAPDH (cat. no. ab9485; dilution, 1:1,000) were purchased from Abcam (Shanghai, China). All additional chemicals and reagents were of analytical grade.

Isolation, purification and identification of CYT. $X$. strumarium fruits were purchased from the Tongrentang Chinese herbal medicine store (Taiyuan, China), and their identity was verified by professor Xiaoming Guo affiliated to the Department of Traditional Chinese Medicine of the Shanxi Cardiovascular Hospital (Taiyuan, China). A voucher specimen was deposited in the herbarium of the Shanxi Cardiovascular Hospital (specimen no. SP1507-07a). The dried fruits of $X$. strumarium were powdered and extracted with $75 \% \mathrm{EtOH}$ by refluxing three times for $2 \mathrm{~h}$ each time (solid: liquid ratio, 1:10 w/v). The extracts were then filtered, and the solvent $(75 \% \mathrm{EtOH})$ was evaporated at $50^{\circ} \mathrm{C}$ under reduced pressure in a vacuum using a vacuum rotary evaporator (Model, CA-1115D; EYELA; Tokyo Rikakikai Co., Ltd., Tokyo, Japan). The residue was successively extracted with petroleum ether, ethyl acetate and n-butanol. Based on a previous report (11), the n-butanol fraction was selected and eluted through silica gel (100-200 mesh) with ethyl acetate and $\mathrm{MeOH}$ (at ratios of 20:1, 15:1, 12:1, 10:1, 8:1, 5:1, 2:1 and $1: 2$ ), and a series of sub-fractions (I-IV) were obtained based on the Thin-layer chromatography analysis. Fraction IV was subjected again to a series of chromatographic separation techniques, including silica gel columns (200-300 mesh) (Qingdao Haiyang Chemical Co., Ltd., Qingdao, China)

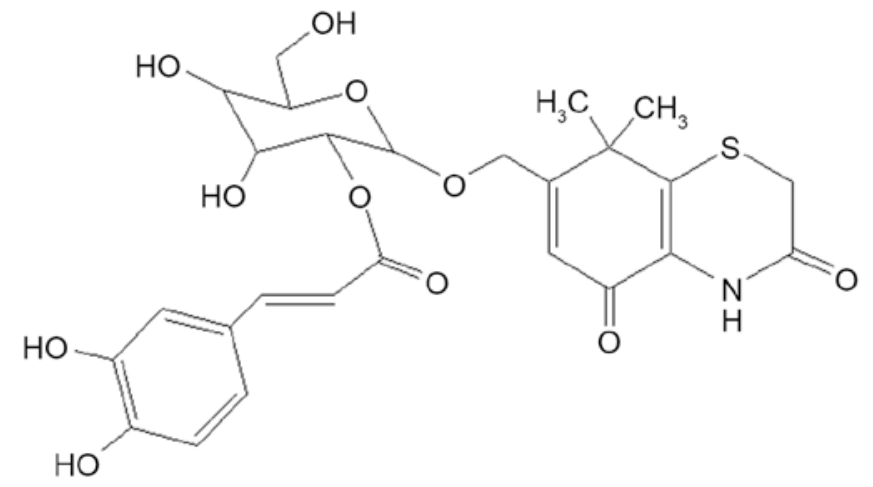

Figure 1. Chemical structure of caffeoylxanthiazonoside.

and Sephadex LH-20 media (GE Healthcare Life Sciences; Little Chalfont, UK) and eluted with pure $\mathrm{MeOH}$ to purify CYT. The molecular structure of CYT is presented in Fig. 1. Purified CYT ( $5 \mathrm{mg}$ for ${ }^{1} \mathrm{H}, 20 \mathrm{mg}$ for ${ }^{13} \mathrm{C}$ ) was identified by ${ }^{1} \mathrm{H}-\mathrm{NMR}$ and ${ }^{13} \mathrm{C}-\mathrm{NMR}$ recorded on Bruker AVANCE-III $\left(600 \mathrm{MHz}\right.$ for ${ }^{1} \mathrm{H}$ and $150 \mathrm{MHz}$ for ${ }^{13} \mathrm{C}$ ) spectrometer. The size of the NMR tube was $5 \times 177.8 \mathrm{~mm}$ and the speed of rotation was $20 \mathrm{~Hz}$. Data were acquired and processed using the Bruker program TopSpin 2.1. The results were confirmed by comparing with a previous study (12). An Agilent 1260 High-performance liquid chromatography system (Agilent Technologies, Inc., Santa Clara, CA, USA) was used to determine the purity of isolated CYT. Sample separation was performed on a Diamonsil ODS column $(250 \times 4.6 \mathrm{~mm})$ at $35^{\circ} \mathrm{C}$. The mobile phase was consisted of acetonitrile $(10 \%)$ and $0.1 \%$ formic acid water solution (90\%). The flow rate was $1.0 \mathrm{ml} / \mathrm{min}$ and the injection volume was $10.0 \mu \mathrm{l}$. The results demonstrated that sample extracts were $>98 \%$ pure.

Animals. A total of 80 male Sprague-Dawley (SD) rats (210 $\pm 20 \mathrm{~g}$; aged 6-7 weeks old) and $10 \mathrm{SD}$ rats $(8 \pm 1 \mathrm{~g}$; aged1-3 days) were purchased from the Shanghai Laboratory Animal Research Centre (Shanghai, China). Throughout the experimental period, rats were housed under controlled conditions at $21 \pm 2^{\circ} \mathrm{C}$ with 12 -h light/dark cycles, and access to a standard pellet diet (Nestlé Purina PetCare Company, St. Louis, MO, USA) and water ad libitum. The rats were maintained on this diet for 1 week prior to the initiation of experimental procedures. All experimental protocols employed in the present study were approved by the Animal Ethics Committee at Shanxi Medical University (Taiyuan, China).

Generation of the CHF model. Rats were divided into the following 5 groups at random ( $\mathrm{n}=16$ rats/group): Sham group, $\mathrm{CHF}$ group, and three CYT treatment groups where $\mathrm{CHF}$ rats were administered with 10,20 and $40 \mathrm{mg} / \mathrm{kg} /$ day CYT, respectively. $\mathrm{CHF}$ model rats were generated by ligating the left anterior descending (LAD) coronary artery, according to the methods described previously $(13,14)$. Briefly, rats were first anaesthetized by intraperitoneal injection of pentobarbital (40 mg/kg). They were subsequently intubated and ventilated with an automatic breathing machine (Shanghai Yuyan Instruments, Co., Ltd., Shanghai, China) using the following parameters: Respiratory rate, 80 cycles/min; tidal volume, 
4-6 $\mathrm{ml}$; respiratory ratio, $1: 1$. The pericardium was then opened under sterile conditions, the heart was exteriorized, and the LAD coronary artery was ligated rapidly. Rats in the sham group underwent the identical surgical procedure without ligation of the LAD coronary artery. Rats were monitored for $24 \mathrm{~h}$ post-surgery, and those that survived were selected for subsequent experiments ( $\mathrm{n}=10$ rats/group).

In the CYT-treated groups, rats were administered with intraperitoneal injections of 10,20 or $40 \mathrm{mg} / \mathrm{kg} /$ day CYT continuously for 8 weeks, while rats in the sham and $\mathrm{CHF}$ model groups were administered with an equal volume of saline. Following 8 weeks of treatment, the cardiac functions of rats were examined. In addition, rats were anesthetized by intraperitoneal injection of $40 \mathrm{mg} / \mathrm{kg}$ pentobarbital, and blood samples were collected from the abdominal aorta. Furthermore, heart tissues were collected for the subsequent biochemical analyses.

Determination of cardiac function. A cardiac sonography was performed using a GE Vivid i Portable Ultrasound System (GE Healthcare Life Sciences, Shanghai, China) with a 12-MHz linear transducer (12 1), according to the methods described previously (15). Rats were first anesthetized by intraperitoneal injection of $40 \mathrm{mg} / \mathrm{kg}$ pentobarbital and fixed in a supine position. Following removal of the chest fur, the detector of the ultrasound system was placed on the left side of the chest. The results were recorded using the workstation supplied by the portable ultrasound system. This was used to measure the following cardiac function indexes: Ejection fraction (EF), heart rate (HR), fractional shortening (FS) and cardiac output $(\mathrm{CO})$.

Determination of TNF- $\alpha, I L-6$ and IL- $\beta$ levels in cardiac tissues. The heart tissues of rats were collected and homogenized in RIPA lysis buffer $(1: 10, \mathrm{w} / \mathrm{v})$, and centrifuged at $6,000 \mathrm{x} \mathrm{g}$ for $15 \mathrm{~min}$ at $4^{\circ} \mathrm{C}$. The level of TNF- $\alpha$, IL- 6 and IL- $\beta$ cytokines in heart tissues was determined by using commercial ELISA kits according to the manufacturer's instructions (R\&D Systems China Co., Ltd.). The absorbance was measured at $450 \mathrm{~nm}$ using a microplate reader (Bio-Rad Laboratories, Inc., Hercules, CA, USA).

Determination of serum $\mathrm{LDH}$ and $\mathrm{CK}$ levels. Blood samples were collected from the abdominal aorta, and the serum was separated from whole blood by high-speed centrifugation at $6,000 \mathrm{x} g$ for $15 \mathrm{~min}$ at $4^{\circ} \mathrm{C}$. The level of myocardial enzymes, $\mathrm{LDH}$ and $\mathrm{CK}$, were measured using commercial assay kits according to the manufacturer's instructions (Nanjing Jiancheng Bioengineering Institute). The absorbance was measured at $340 \mathrm{~nm}$ using a microplate reader (Bio-Rad Laboratories, Inc.)

Isolation of cardiac microvascular endothelial cells (CMECs) and culture. CMECs were isolated from the heart tissues of 10 SD rats ( $8 \pm 1 \mathrm{~g}$; aged 1-3 days) using the methods described previously (16). The rats were sacrificed, and then the hearts of the rats were separated and sterilized with $70 \% \mathrm{EtOH}$. CMECs were subsequently isolated from heart tissues by incubating tissues in $0.2 \%$ type II collagenase and $0.08 \%$ trypsin in Hank's balanced salt solution for $35 \mathrm{~min}$ at $37^{\circ} \mathrm{C}$. The solution was filtered and centrifuged at $1,000 \mathrm{x}$ g for $10 \mathrm{~min}$ at $4^{\circ} \mathrm{C}$. to remove myocytes. The CMECs were then resuspended in DMEM-F12 medium containing 20\% FBS, and incubated in culture flasks for $2 \mathrm{~h}$ at $37^{\circ} \mathrm{C}$. The cells were subsequently washed carefully with phosphate buffered saline three times (30 sec each time) to remove any non-adherent cells and debris. Isolated CMECs formed confluent monolayers at 5-7 days of culture.

Determination of TNF- $\alpha, I L-1 \beta$ and IL- 6 levels in CMECs. CMECs $\left(1 \times 10^{5}\right.$ cells $\left./ \mathrm{ml}\right)$ were seeded in $96-$ well plates. The cells in experimental groups were treated with 20,40 or $80 \mu \mathrm{g} / \mathrm{ml} \mathrm{CYT}$ for $24 \mathrm{~h}$ at $37^{\circ} \mathrm{C}$ in the presence of $100 \mathrm{ng} / \mathrm{ml}$ lipopolysaccharide (LPS). The cells in the control group were only cultured in DMEM-F12 medium containing 20\% FBS, whereas the model group cells were cultured in DMEM with LPS stimulation $(100 \mathrm{ng} / \mathrm{ml})$. Cell culture supernatants were collected and centrifuged at $6,000 \mathrm{x}$ g for $15 \mathrm{~min}$ at $4^{\circ} \mathrm{C}$. The levels of TNF- $\alpha$, IL-1 $\beta$ and IL- 6 in the cell culture supernatants were subsequently measured using the same commercial assay kits as mentioned above according to the manufacturer's instructions (R\&D SystemsChina Co., Ltd., Shanghai, China). The absorbance was measured at $450 \mathrm{~nm}$ using a microplate reader (Bio-Rad Laboratories, Inc.).

Western blotting. CMECs $\left(1 \times 10^{5}\right.$ cells $\left./ \mathrm{ml}\right)$ were seeded in 24-well plates. The experimental groups were treated with 20,40 or $80 \mu \mathrm{g} / \mathrm{ml} \mathrm{CYT}$ and $100 \mathrm{ng} / \mathrm{ml} \mathrm{LPS.} \mathrm{The}$ control group was only cultured in DMEM, whereas the model group was cultured in DMEM with LPS stimulation (100 ng/ml). Following incubation at $37^{\circ} \mathrm{C}$ for $24 \mathrm{~h}$, nuclear and cytoplasmic proteins were extracted from CMECs by using the nuclear and cytoplasmic protein extraction kits (cat. no. P0027; Beyotime Institute of Biotechnology) according to the manufacturer's instructions. The protein concentration was determined using a BCA protein assay kit. For each sample, $30 \mu \mathrm{g}$ total proteins were separated using 10\% SDS-PAGE and blotted onto polyvinylidene difluoride membranes (EMD Millipore, Billerica, MA, USA). The membranes were blocked with $5 \%$ non-fat milk at room temperature. They were subsequently incubated with the corresponding primary antibodies including NF- $\kappa \mathrm{B}$ p65 (dilution 1:1,000), IкB (dilution 1:1,000), histone H1 (dilution 1:1,000) and GAPDH (dilution 1:1,000) as mentioned above for $24 \mathrm{~h}$ at $4^{\circ} \mathrm{C}$, followed by incubation with horseradish peroxidase-conjugated goat anti-mouse secondary antibody (cat. no. A0216; 1:1,000 dilution; Beyotime Institute of Biotechnology) for $1 \mathrm{~h}$ at room temperature. Protein bands were subsequently visualized using the Beyo-ECL Plus reagent (Beyotime Institute of Biotechnology). Target protein expression levels were normalized to that of GAPDH, and the fold-change in expression was determined.

Statistical analysis. The results are expressed as the mean \pm standard deviation $(n=3)$, and statistical analyses were performed using SPSS software (version, 17.0; SPSS, Inc., Chicago, IL, USA). The results were analyzed by one-way analysis of variance and Dunnett multiple comparisons test. $\mathrm{P}<0.05$ was considered to indicate a statistically significant difference. 

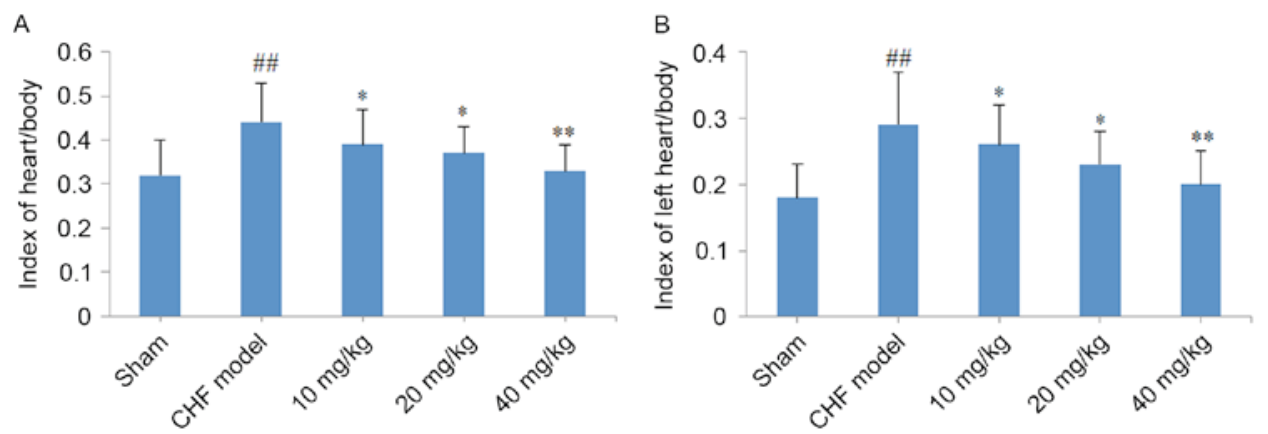

Figure 2. Effect of caffeoylxanthiazonoside on (A) heart weight/body weight and (B) left heart weight/body weight indexes in CHF model rats. The results are expressed as mean \pm standard deviation $(\mathrm{n}=10) .{ }^{\# \#} \mathrm{P}<0.01$ vs. sham group; ${ }^{*} \mathrm{P}<0.05 ;{ }^{* *} \mathrm{P}<0.01$ vs. CHF model group. CHF, chronic heart failure.


Figure 3. Effect of caffeoylxanthiazonoside on (A) EF, (B) FS, (C) HR and (D) CO indexes in CHF model rats. The results are expressed as the mean \pm standard deviation $(\mathrm{n}=10)$. ${ }^{\# /} \mathrm{P}<0.01$ vs. sham group; ${ }^{*} \mathrm{P}<0.05$ and ${ }^{* *} \mathrm{P}<0.01$ vs. CHF model group. EF, ejection fraction; FS, fractional shortening; HR, heart rate; cardiac output; CHF, chronic heart failure; BPM, beats per minute.

\section{Results}

Effect of CYT on the heart-body weight index. As demonstrated in Fig. 2, a significant increase in the heart/body weight and left heart/body weight indexes $(\mathrm{P}<0.01)$ were observed in the CHF model group when compared with the sham group. Notably, cardiac hypertrophy was reversed following treatment of $\mathrm{CHF}$ model rats with $\mathrm{CYT}$ for 8 weeks, as indicated by the significant reduction in the heart/body weight and left heart/body weight indexes in the 10,20 and $40 \mathrm{mg} / \mathrm{kg}$ CYT-treated groups when compared with the CHF model group $(\mathrm{P}<0.05, \mathrm{P}<0.05$ and $\mathrm{P}<0.01$, respectively; Fig. 2).

Effect of CYT on cardiac function in CHF model rats. When compared with rats in the sham group, the FS, EF, CO and HR cardiac function indexes were significantly decreased in $\mathrm{CHF}$ rats $(\mathrm{P}<0.01$; Fig. 3$)$. By contrast, treatment of $\mathrm{CHF}$ model rats with 20 or $40 \mathrm{mg} / \mathrm{kg}$ CYT for 8 weeks was associated with a significant increase in the EF and FS indexes when compared with untreated CHF model rats $(20 \mathrm{mg} / \mathrm{kg}, \mathrm{P}<0.05$;
$40 \mathrm{mg} / \mathrm{kg}, \mathrm{P}<0.01$; Fig. 3A and B). Notably, HR was significantly increased following treatment of $\mathrm{CHF}$ model rats with 10,20 and $40 \mathrm{mg} / \mathrm{kg}$ CYT $(\mathrm{P}<0.05, \mathrm{P}<0.05$ and $\mathrm{P}<0.01$, respectively; Fig. 3C). In addition, the $\mathrm{CO}$ index was significantly increased following treatment with increasing concentrations of CYT (P<0.05; Fig. 3D).

Effect of CYT on the level of TNF- $\alpha, I L-1 \beta$ and IL- 6 in cardiac tissues from $\mathrm{CHF}$ model rats. As demonstrated in Fig. 4, the production of TNF- $\alpha$, IL-1 $\beta$ and IL- 6 in cardiac tissues was significantly increased in $\mathrm{CHF}$ model rats when compared with sham group rats $(\mathrm{P}<0.01)$. By contrast, oral administration of 10,20 or $40 \mathrm{mg} / \mathrm{kg} \mathrm{CYT}$ for 8 weeks was associated with a significant and dose-dependent decrease in the production of these pro-inflammatory cytokines when compared with rats in the CHF model group ( $\mathrm{P}<0.01$; Fig. 4$)$.

Effect of CYT on LDH and CK levels in CHF model rats. As demonstrated in Fig. 5, serum LDH and CK levels in rats from the CHF model group were significantly elevated when 

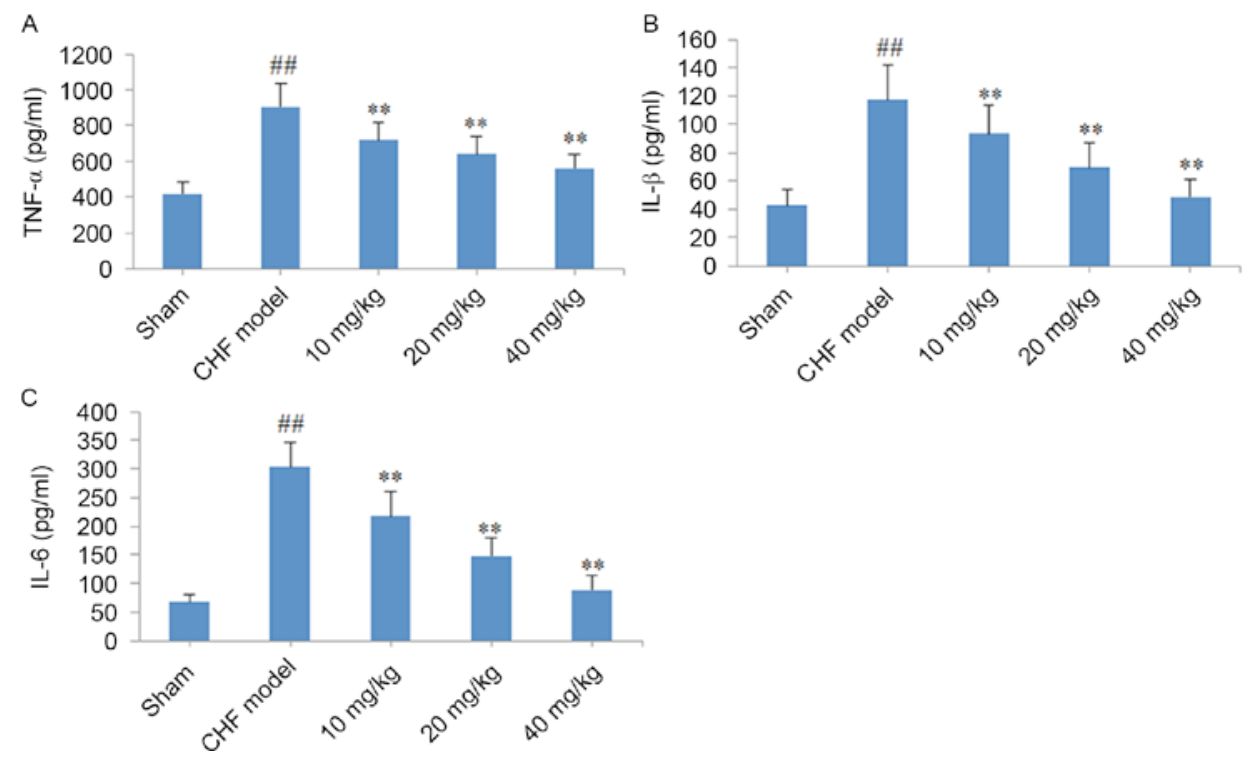

Figure 4. Effect of caffeoylxanthiazonoside on (A) TNF- $\alpha$, (B) IL-1 $\beta$ and (C) IL-6 protein levels in the heart tissues from CHF model rats. The results are expressed as the mean \pm standard deviation $(\mathrm{n}=10) .{ }^{\# \#} \mathrm{P}<0.01$ vs. sham group; ${ }^{* *} \mathrm{P}<0.01$ vs. CHF model group. TNF- $\alpha$, tumor necrosis factor- $\alpha$; IL, interleukin; CHF, chronic heart failure.
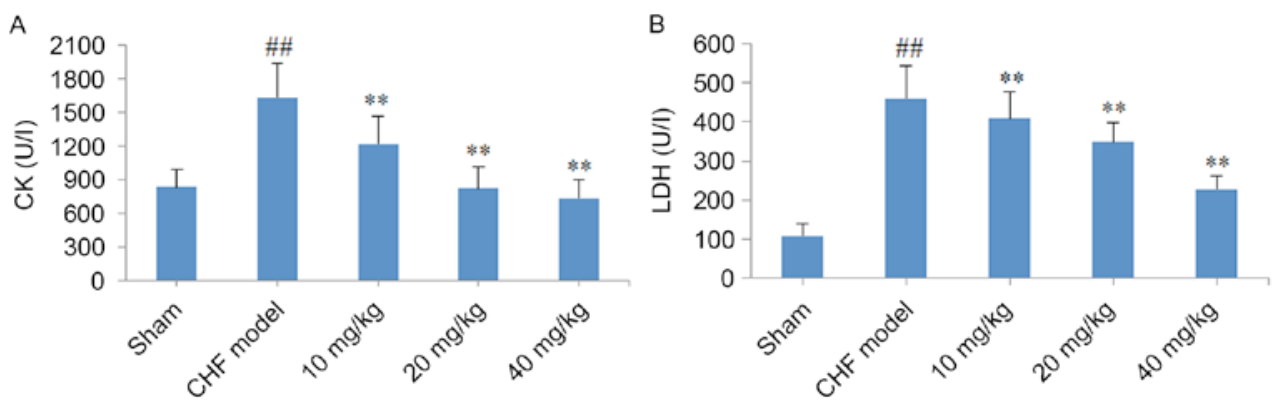

Figure 5. Effect of caffeoylxanthiazonoside on serum (A) CK and (B) LDH levels in CHF model rats. The results are expressed as the mean \pm standard deviation $(\mathrm{n}=10) .{ }^{\# \#} \mathrm{P}<0.01$ vs. sham group; ${ }^{* *} \mathrm{P}<0.01$ vs. CHF model group. $\mathrm{CK}$, creatine kinase; $\mathrm{LDH}$, lactate dehydrogenase; CHF, chronic heart failure.

compared with those in the sham group $(\mathrm{P}<0.01)$. By contrast, treatment of CHF model rats with 10,20 and $40 \mathrm{mg} / \mathrm{kg}$ CYT for 8 weeks was associated with a significant and dose-dependent reduction in serum $\mathrm{CK}$ and $\mathrm{LDH}$ levels when compared with untreated CHF model rats $(\mathrm{P}<0.01$; Fig. 5).

Effect of CYT on TNF- $\alpha, I L-1 \beta$ and IL- 6 levels in CMECs. When compared with the control group, the level of TNF- $\alpha$, IL-1 $\beta$ and IL- 6 pro-inflammatory cytokines in the model group were significantly elevated $(\mathrm{P}<0.01$; Fig. 6$)$. Consistent with the observed expression of these factors in the heart tissues from CYT-treated CHF model rats, treatment of CMECs with 40 or $80 \mu \mathrm{g} / \mathrm{ml} \mathrm{CYT} \mathrm{significantly} \mathrm{decreased} \mathrm{the} \mathrm{level} \mathrm{of}$ TNF- $\alpha(\mathrm{P}<0.01)$, and treatment with 20,40 or $80 \mu \mathrm{g} / \mathrm{ml}$ CYT significantly decreased the levels of IL-1 $\beta$ and IL-6 $(\mathrm{P}<0.01)$ when compared with the model group.

Effect of CYT on the expression of $N F-\kappa B$ signaling pathway protein factors in CMECs. As demonstrated in Fig. 7, the protein expression levels of nuclear NF- $\kappa B$ p65 in LPS-induced CMECs were markedly elevated when compared with normal cells, indicating increased inflammation. By

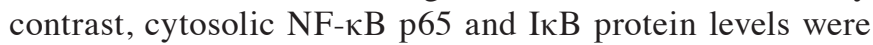

reduced in LPS-induced model group cells when compared with untreated controls (Fig. 7). Notably, nuclear NF-кB p65 expression was significantly decreased following treatment of LPS-stimulated CMECs with 20,40 and $80 \mu \mathrm{g} / \mathrm{ml} \mathrm{CYT} \mathrm{when}$ compared with the untreated model group. By contrast, the cytosolic levels of NF- $\kappa$ B p 65 and I $\kappa$ B protein were markedly increased following treatment with 20,40 or $80 \mu \mathrm{g} / \mathrm{ml} \mathrm{CYT}$ when compared with the model group (Fig. 7).

\section{Discussion}

The results presented in the current study suggest that CYT may exert significant cardioprotective effects in vivo and in vitro. In addition, the results indicate that these effects may be mediated by inhibition of the release of inflammatory mediators, myocardial enzymes and the expression of NF- $\mathrm{KB}$ signaling pathway proteins.

Previous reports have demonstrated that $\mathrm{CK}$ and $\mathrm{LDH}$ are sensitive markers of myocardial damage $(17,18)$. Notably, CK levels serve a vital role in the early diagnosis of myocardial infarction and additional cardiac diseases, and it is known to be a gold standard marker of cardiomyocyte injury $(19,20)$. In the present study, the serum levels of $\mathrm{CK}$ and $\mathrm{LDH}$ were 

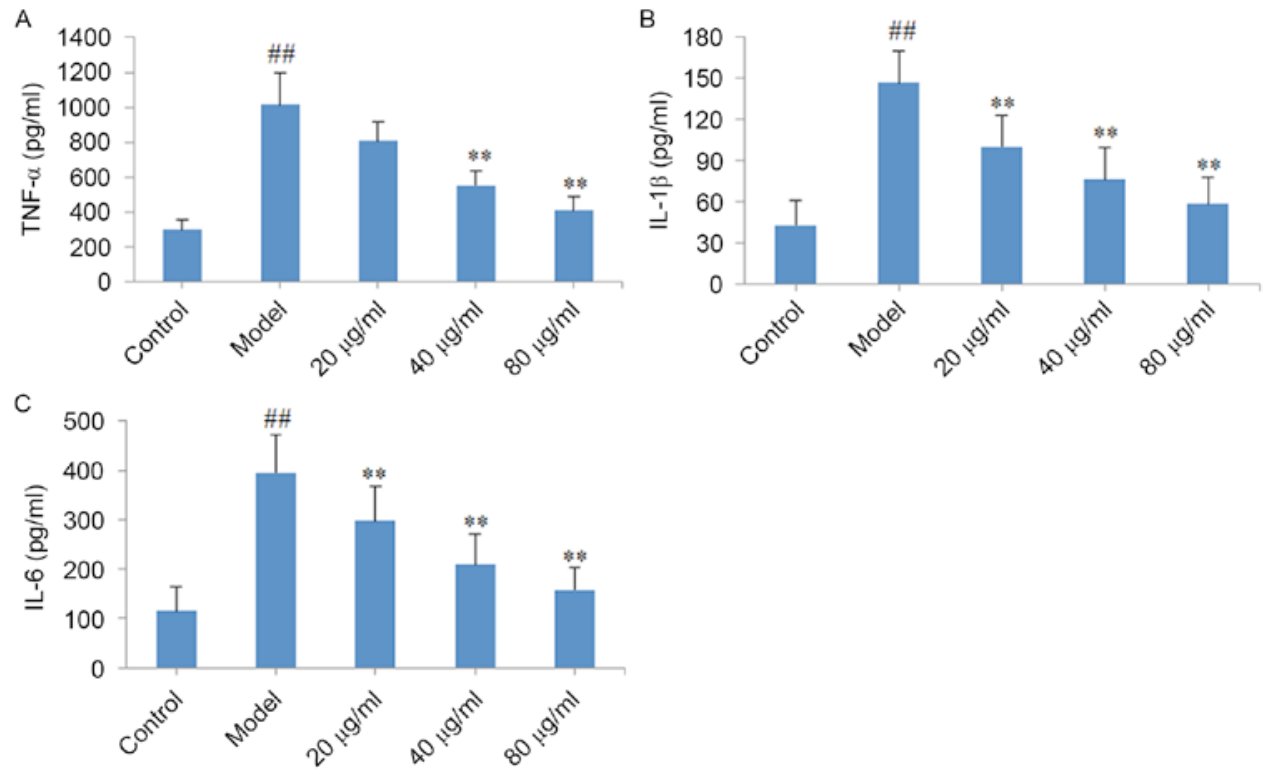

Figure 6. Effect of caffeoylxanthiazonoside on (A) TNF- $\alpha$, (B) IL-1 $\beta$ and (C) IL-6 protein levels in LPS-stimulated CMECs. The results are expressed as the mean \pm standard deviation $(n=4) .{ }^{\# \#} \mathrm{P}<0.01$ vs. control group; ${ }^{* *} \mathrm{P}<0.01$ vs. model group. TNF- $\alpha$, tumor necrosis factor- $\alpha$; IL, interleukin; LPS, lipopolysaccharide; CMECs, cardiac microvascular endothelial cells.
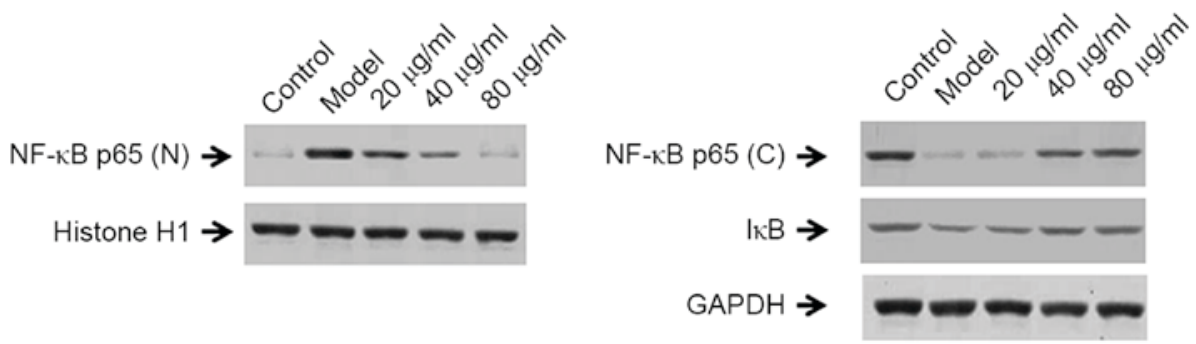

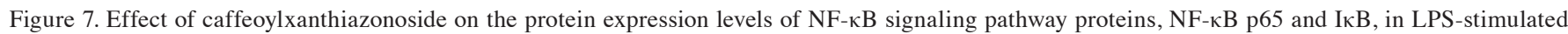
CMECs, as determined by western blotting analysis. NF- $\mathrm{kB}$, nuclear factor- $\mathrm{\kappa B}$; LPS, lipopolysaccharide; CMECs, cardiac microvascular endothelial cells; $(\mathrm{N})$, nuclear; (C), cytoplasmic.

significantly increased following LAD surgery; however, this increase was attenuated by treatment with CYT. In addition, the results demonstrated that CYT administration significantly decreased the whole heart/body weight and left heart/body weight ratios, and significantly increased cardiac function parameters, including FS, EF, CO and HR. This indicates that CYT may exert notable cardioprotective effects in LAD surgery-induced CHF model rats.

Previous epidemiological studies have reported that inflammatory lesions serve a central role in ischemia/reperfusion (I/R)-induced cardiac injury, and cytokines have been demonstrated to be closely associated with the inflammatory response in the progress of $\mathrm{I} / \mathrm{R}$-induced cardiac injury $(21,22)$. It has been demonstrated that $I / R$ increases the relative levels of various cytokines in the myocardium, including TNF- $\alpha$, IL-1 $\beta$ and IL-6 $(18,23)$. Taking these observations into consideration, the level of these cytokines in the cardiac tissues of CYT-treated CHF model rats was determined in the present study. The results indicated that the expression levels of these pro-inflammatory cytokines were significantly increased in CHF model rats when compared with those in the sham group. Notably, treatment of CHF model rats with
CYT effectively reversed this increase in TNF- $\alpha$, IL-1 $\beta$ and IL-6 expression. Therefore, the authors of the present study hypothesize that the cardioprotective effects of CYT may be partly mediated by inhibition of pro-inflammatory mediators.

The cardioprotective effects of CYT were further verified using an in vitro model of cardiac inflammation, whereby CMECs were induced with LPS. The results demonstrated that CYT treatment decreased the levels of TNF- $\alpha$, IL- $1 \beta$ and IL-6 in LPS-induced CMECs. An increasing number of studies have revealed that the $\mathrm{NF}-\kappa \mathrm{B}$ signaling pathway serves an important role in regulating inflammatory responses $(16,24)$.

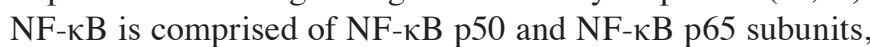
which are generally localized in the cytoplasm together with its inhibitor, $\mathrm{I} \kappa \mathrm{B}$. NF- $\kappa \mathrm{B}$ is transported to the nucleus following dissociation with $\mathrm{I} \kappa \mathrm{B}$, where it exerts its function as a transcription factor and induces an inflammatory response $(25,26)$. The results of the present study indicated that CYT repressed nuclear $\mathrm{NF}-\kappa \mathrm{B}$ p 65 expression, and increased cytoplasmic NF- $\mathrm{B}$ p 65 and $\mathrm{I} \kappa \mathrm{B}$ expression. These results suggest that $\mathrm{CYT}$ may regulate the $\mathrm{NF}-\kappa \mathrm{B}$ signaling pathway in CMECs. 
In conclusion, the results of the current study provide experimental evidence that CYT exerts cardioprotective effects in a rat model of CHF induced by LAD surgery. The mechanisms underlying the effects of CYT may involve suppression of inflammatory mediators and members of the $\mathrm{NF}-\kappa \mathrm{B}$ signaling pathway.

\section{Acknowledgements}

The present study was funded by a grant from the Natural Science Foundation of China (no. 81500285) and the 331 Early Career Researcher Grant of Shanxi Medical University (no. 201409).

\section{References}

1. Shimokawa H, Miura M, Nochioka K and Sakata Y: Heart failure as a general pandemic in Asia. Eur J Heart Fail 17: 884-892, 2015.

2. Heusch G, Libby P, Gersh B, Yellon D, Böhm M, Lopaschuk G and Opie L: Cardiovascular remodelling in coronary artery disease and heart failure. Lancet 383: 1933-1943, 2014.

3. Owan TE, Hodge DO, Herges RM, Jacobsen SJ, Roger VL and Redfield MM: Trends in prevalence and outcome of heart failure with preserved ejection fraction. N Engl J Med 355: 251-259, 2006.

4. Li X, Zhang J, Huang J, Ma A, Yang J, Li W, Wu Z, Yao C, Zhang Y, Yao W, et al: A multicenter, randomized, double-blind, parallel-group, placebo-controlled study of the effects of qili qiangxin capsules in patients with chronic heart failure. J Am Coll Cardiol 62: 1065-1072, 2013.

5. Guo N, Yang D, Wang X, Dai J, Wang M and Lei Y: Metabonomic study of chronic heart failure and effects of Chinese herbal decoction in rats. J Chromatogr A 1362: 89-101, 2014.

6. Parang P, Singh B and Arora R: Metabolic modulators for chronic cardiac ischemia. J Cardiovasc Pharmacol Ther 10: 217-223, 2015

7. Marcinkiewicz-Siemion M, Ciborowski M, Kretowski A, Musial WJ and Kaminski KA: Metabolomics-a wide-open door to personalized treatment in chronic heart failure? Int J Cardiol 219: 156-163, 2016

8. Piloto Ferrer J, Cozzi R, Cornetta T, Stano P, Fiore M, Degrassi F, De Salvia R, Remigio A, Francisco M, Quiñones O, et al: Xanthium strumarium L. extracts produce DNA damage mediated by cytotoxicity in in vitro assays but does not induce micronucleus in mice. Biomed Res Int 2014: 575197, 2014.

9. Chen F, Hao F, Li C, Gou J, Lu D, Gong F, Tang H and Zhang Y: Identifying three ecological chemotypes of Xanthium strumarium glandular trichomes using a combined NMR and LC-MS method. PLoS One 8: e76621, 2013.

10. Han T, Li HL, Zhang QY, Han P, Zheng HC, Rahman K and Qin LP: Bioactivity-guided fractionation for anti-inflammatory and analgesic properties and constituents of Xanthium strumarium L. Phytomedicine 14: 825-829, 2007.

11. Peng W, Ming QL, Han P, Zhang QY, Jiang YP, Zheng CJ, Han T and Qin LP: Anti-allergic rhinitis effect of caffeoylxanthiazonoside isolated from fruiats of Xanthium strumarium L. in rodent animals. Phytomedicine 21: 824-829, 2014.

12. Qin L, Han T, Li H, Zhang Q and Zheng H: A new thiazinedione from Xanthium strumarium. Fitoterapia 77: 245-246, 2006.
13. Zhu GQ, Gao L, Li Y, Patel KP, Zucker IH and Wang W: AT1 receptor mRNA antisense normalizes enhanced cardiac sympathetic afferent reflex in rats with chronic heart failure. Am J Physiol Heart Circ Physiol 287: H1828-H1835, 2004.

14. Wang HJ, Zhang F, Zhang Y, Gao XY, Wang W and Zhu GQ: AT1 receptor in paraventricular nucleus mediates the enhanced cardiac sympathetic afferent reflex in rats with chronic heart failure. Auton Neurosci 121: 56-63, 2015

15. Xing L, Jiang M, Dong L, Gao J, Hou Y, Bai G and Luo G: Cardioprotective effects of the YiQiFuMai injection and isolated compounds on attenuating chronic heart failure via $N F-\kappa B$ inactivation and cytokine suppression. J Ethnopharmacol 148: 239-245, 2013.

16. Yang C, Wu K, Li SH and You Q: Protective effect of curcumin against cardiac dysfunction in sepsis rats. Pharm Biol 51: 482-487, 2013.

17. Badole SL, Chaudhari SM, Jangam GB, Kandhare AD and Bodhankar SL: Cardioprotective activity of Pongamia pinnata in streptozotocin-nicotinamide induced diabetic rats. Biomed Res Int 2015: 403291, 2015.

18. Gu M, Zheng AB, Jin J, Cui Y, Zhang N, Che ZP, Wang Y, Zhan J and Tu WJ: Cardioprotective effects of genistin in rat myocardial ischemia-reperfusion injury studies by regulation of P2X7/NF- $\kappa \mathrm{B}$ pathway. Evid Based Complement Alternat Med 2016: 5381290, 2016.

19. Xia A, Xue Z, Li Y, Wang W, Xia J, Wei T, Cao J and Zhou W: Cardioprotective effect of betulinic acid on myocardial ischemia reperfusion injury in rats. Evid Based Complement Alternat Med 2014: 573745, 2014.

20. Hu T, Wei G, Xi M, Yan J, Wu X, Wang Y, Zhu Y, Wang C and Wen A: Synergistic cardioprotective effects of Danshensu and hydroxysafflor yellow A against myocardial ischemia-reperfusion injury are mediated through the Akt/Nrf2/HO-1 pathway. Int J Mol Med 38: 83-94, 2016

21. Saini HK, Xu YJ, Zhang M, Liu PP, Kirshenbaum LA and Dhalla NS: Role of tumour necrosis factor-alpha and other cytokines in ischemia-reperfusion-induced injury in the heart. Exp Clin Cardiol 10: 213-222, 2015.

22. Yuan X, Niu HT, Wang PL, Lu J, Zhao H, Liu SH, Zheng QS and Li CG: Cardioprotective effect of Licochalcone D against myocardial ischemia/reperfusion injury in langendorff-perfused rat hearts. PLoS One 10: e0128375, 2015.

23. Garcia I, Olleros ML, Quesniaux VF, Jacobs M, Allie N, Nedospasov SA, Szymkowski DE and Ryffel B: Roles of soluble and membrane TNF and related ligands in mycobacterial infections: Effects of selective and non-selective TNF inhibitors during infection. Adv Exp Med Biol 691: 187-201, 2011.

24. Han Y, Zhou M, Xing L, Jiang M, Bai G and Luo G: Identification of NF- $\kappa$ B inhibitors in Qishenyiqi dropping pills for myocardial infarction treatment based on bioactivity-integrated UPLC-Q/TOF MS. Biomed Chromatogr 29: 1612-1618, 2015.

25. He CL, Yi PF, Fan QJ, Shen HQ, Jiang XL, Qin QQ, Song Z, Zhang C, Wu SC, Wei XB, et al: Xiang-Qi-Tang and its active components exhibit anti-inflammatory and anticoagulant properties by inhibiting MAPK and NF- $\mathrm{KB}$ signaling pathways in LPS-treated rat cardiac microvascular endothelial cells. Immunopharmacol Immunotoxicol 35: 215-224, 2013.

26. Shi Q, Cao J, Fang L, Zhao H, Liu Z, Ran J, Zheng X, Li X, Zhou Y, Ge D, et al: Geniposide suppresses LPS-induced nitric oxide, PGE2 and inflammatory cytokine by downregulating $\mathrm{NF}-\kappa \mathrm{B}, \mathrm{MAPK}$ and AP-1 signaling pathways in macrophages. Int Immunopharmacol 20: 298-306, 2014 